\title{
Characterizing spring emergence of adult Halyomorpha halys using experimental overwintering shelters and commercial pheromone traps
}

\author{
J. Christopher Bergh ${ }^{1} *$, William R. Morrison $\mathrm{III}^{2}$, Shimat V. Joseph ${ }^{3}$ \& Tracy C. Leskey ${ }^{2}$ \\ ${ }^{1}$ Virginia Tech, Alson H. Smith, Jr. Agricultural Research and Extension Center, 595 Laurel Grove Road, Winchester, VA \\ 22602, USA, ${ }^{2}$ USDA ARS Appalachian Fruit Research Station, 2217 Wiltshire Road, Kearneysville, WV 25430, USA, and \\ ${ }^{3}$ University of California Cooperative Extension, 1432 Abbott Street, Salinas, CA 93901, USA
}

Accepted: 14 September 2016

Key words: brown marmorated stink bug, Hemiptera, life cycle, Pentatomidae, trapping

\section{Abstract}

\section{Introduction}

Following the detection of the invasive, brown marmorated stink bug, Halyomorpha halys (Stål) (Hemiptera: Pentatomidae), in Allentown, PA, USA, in the late 1990s (Hoebeke \& Carter, 2003), its populations in the MidAtlantic region of the USA remained relatively low for most of the following decade. In mid-summer 2010, a sudden $H$. halys outbreak in much of this region resulted in major crop losses at harvest (Leskey et al., 2012a) and the beginning of its rapid range expansion in North America (www.stopbmsb.org). Beginning in 2011, producers of many affected crops increased their use of broad-spectrum

*Correspondence: Chris Bergh, Virginia Tech AHSAREC, 595 Laurel Grove Road, Winchester, VA 22602, USA. E-mail: cbergh@vt.edu insecticides to mitigate the economic impacts from $H$. halys; this has been most pronounced in some tree fruit crops (Leskey et al., 2012a), resulting in significant disruption of integrated pest management programs and increased occurrences of secondary pest outbreaks.

Since 2010, research on $H$. halys in North America has sought to enable producers of affected crops to respond effectively to this threat and to resume sustainable pest management practices. Among many other objectives, this extensive initiative has addressed relative crop risk and injury characterization (Leskey et al., 2012a; Joseph et al., 2015; Acebes-Doria et al., 2016a), insecticide effects (Lee et al., 2012; Leskey et al., 2012b, 2013), monitoring tools (Khrimian et al., 2014; Weber et al., 2014; Leskey et al., 2015a; Morrison et al., 2015), and aspects of H. halys physiology and behavior (Lee et al., 2014a; Taylor et al., 
2014; Lee \& Leskey, 2015; Wiman et al., 2015; AcebesDoria et al., 2016b; Morrison et al., 2016; Nielsen et al., 2016). Although some investigations of its overwintering biology have been conducted in Asia (reviewed in Lee et al., 2013), much about this portion of its life cycle in North America remains poorly understood.

As in its native Asian range (Lee et al., 2013), adult $H$. halys in the eastern USA disperse to protected overwintering sites in late September and October, within which they form aggregations of a few to many thousands of individuals. These include natural and anthropogenic harborages, such as under loose bark of fallen trees (Lee et al., 2014b) or rock piles and rocky outcroppings, human-made structures, and many other sites associated with human activity. Its invasion of private residences and other occupied buildings have often created serious nuisance issues during the fall and throughout the winter and spring, when adults enter the living space from the attic or elsewhere (Inkley, 2012), presumably in response to interior sources of heat or light. The distribution of the overwintering population among these many possible sites is unknown, as are the relative contributions of cohorts that settle in different sites to the following years' population. Some portion of the adults that settle in heated and lighted structures may perish prematurely due to starvation and desiccation, whereas the survivorship of those that overwinter in natural settings likely varies according to annual variations in winter temperatures, the thermal buffering capacity of specific sites, and the potential for microhabitat effects created by their aggregations. Cira et al. (2016) determined the supercooling point of overwintering $H$. halys and the effect of sub-freezing temperatures on survivorship and showed that $H$. halys is chill intolerant and exhibits rapidly increasing mortality at temperatures below about $-10{ }^{\circ} \mathrm{C}$.

Reports from Asia suggest that overwintering $H$. halys adults emerge from late March to mid-May when temperatures exceed $10{ }^{\circ} \mathrm{C}$ (reviewed in Lee et al., 2013). In the Mid-Atlantic region of the USA, its spring emergence has been inferred by captures in pheromone-baited traps (Leskey et al., 2015a) and field observations (Leskey et al., 2012a). Photoperiod is considered an important cue for diapause induction and termination in $H$. halys adults (Watanabe, 1979; Yanagi \& Hagihara, 1980; Nielsen et al., 2016) and for the initiation of ovarian development in post-diapause females (Watanabe, 1979).

Empirical measurements of the onset, peak, and duration of $H$. halys emergence in the spring are needed and will be important to future efforts to refine models of its population dynamics and annual risk to crops, especially since Nielsen et al. (2016) noted that the lack of clarity regarding appropriate sampling methods to determine a biofix for initializing such models is a limiting factor at present. Toward that end, it is important to develop methods by which cohorts of overwintering adult $H$. halys can be manipulated systematically. Moreover, the identification of the $H$. halys aggregation pheromone (Khrimian et al., 2014) and a pheromone synergist (Weber et al., 2014), and the development of an effective monitoring trap (Leskey et al., 2015a) afforded opportunities to examine the temporal relationship between emergence and captures in traps, and by extension, whether captures might be used to determine a biofix. Here, we report the results of field experiments conducted between 2012 and 2014 which investigated the temporal pattern of spring emergence of adult $H$. halys from experimental overwintering shelters and adult captures in pheromone-baited traps during the spring emergence period.

\section{Materials and methods}

\section{Plastic overwintering shelters: 2012}

Our initial study in 2012 used shelters constructed from 1-l opaque plastic Nalgene containers $(13.5 \mathrm{~cm}$ high, $11.1 \mathrm{~cm}$ inner diameter; Fisher Scientific, Waltham, MA, USA) with a screw-top lid in which a $9.5-\mathrm{cm}$-diameter hole was cut (Figure 1A). A fitted circle of Whatman No. 1 filter paper lined the container bottom and a cardboard strip $(1.3 \times 10.9 \times 2.5 \mathrm{~cm})$ was laid flat on this. Four cylinders of 4.8-mm-thick cardboard, each of a somewhat smaller diameter and ca. $10.3 \mathrm{~cm}$ high, were inserted vertically into the container and rested on the cardboard strip, leaving a $1.3-\mathrm{cm}$-wide space between them and the container bottom and a central open area into which bugs could be added. The spaces between the walls of cardboard cylinders varied in width, but were generally about $0.5 \mathrm{~cm}$, providing overwintering harborage for adult $H$. halys. The base of the green plastic funnel $(11.8 \mathrm{~cm}$ outer diameter) from Dead-Inn H. halys traps (AgBio, Westminster, CO, USA) fit snugly into the flanged container lid and enabled bugs to exit the container through the hole at the funnel top. A plastic, mushroom-shaped, fluon-coated cap with a hole in the center was placed over the top of the funnel mouth, preventing bugs that exited the container from reentering it. The amount of light that could enter the container was reduced by wrapping black electrician's tape around the ventilation slits in the bottom two-thirds of the funnel and by a fitted black cloth sleeve that covered the opaque container.

\section{Wooden ovenwintering shelters: 2013-2014}

Trials during fall 2012 demonstrated that large numbers of adult $H$. halys that were dispersing to overwintering sites voluntarily settled in the wooden shelters described 

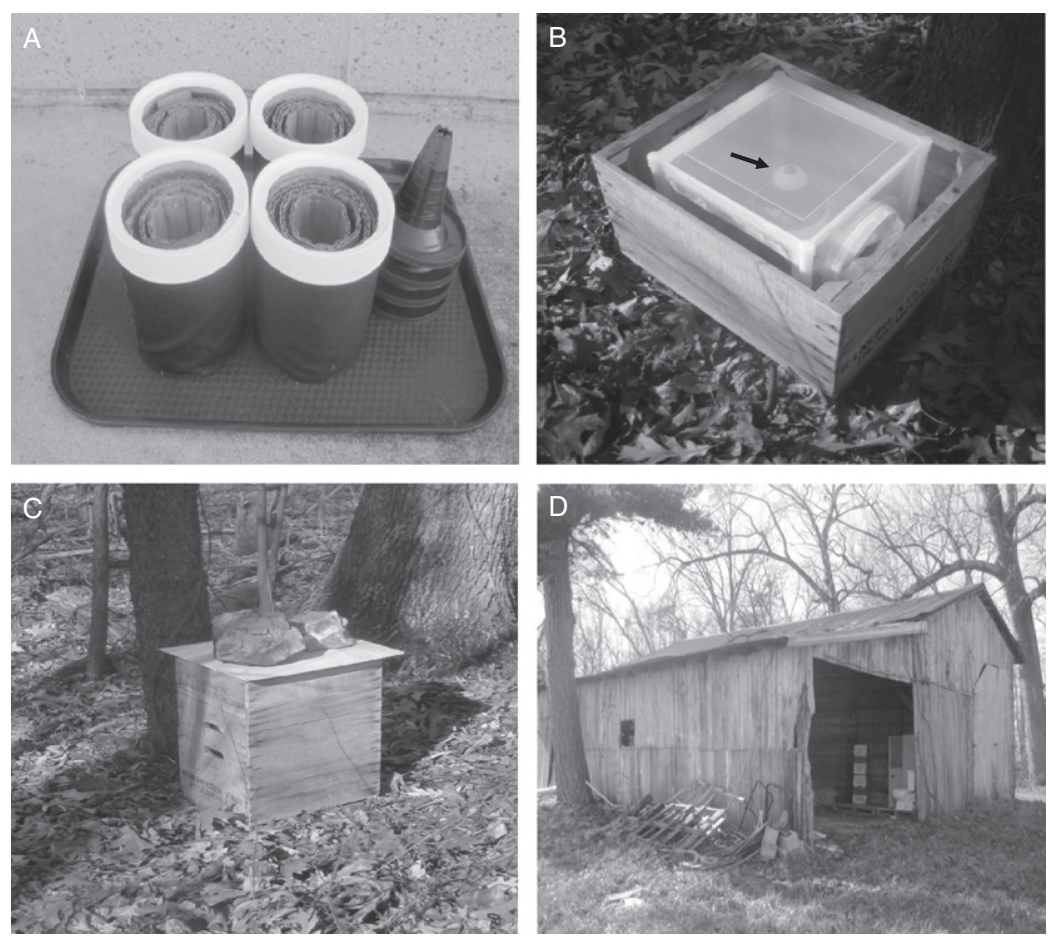

Figure 1 Plastic overwintering shelters used in 2012. (A) With cardboard cylinder inserts; note the black cloth sleeve over shelter base and the plastic funnels that sat atop each. (B) Shelter within a screened cage inside an apple crate; arrow shows the fluon-coated plastic cap that encircled the funnel mouth. (C) Shelter assembly deployed in a woodlot. (D) Representative unheated, unlighted building in which shelter assemblies were deployed.

below. Given the apparent suitability of these shelters to adult $H$. halys seeking an overwintering site, this design was used for studies in 2013 and 2014. These shelters $(19 \times 22 \times 24 \mathrm{~cm})$ were similar in appearance to a medium-sized birdhouse, but with an open bottom, and constructed of 0.6-cm-thick plywood (Figure 2A-D). A shallow-sloped roof that overhung the removable front panel had a $0.6-\mathrm{cm}$ gap between it and the top of the front panel, enabling adults to leave the shelter via this opening or the open bottom. Eighteen cardboard inserts $(0.3 \times 17.8 \times 21.6 \mathrm{~cm}) \quad$ with cardboard spacers $(0.3 \times 17.8 \times 1.3 \mathrm{~cm})$ glued to the surface along both edges of one side were stacked vertically from back to front inside each shelter, filling most of the interior. When the shelters were upright, the inserts rested on horizontal flanges along the bottom of both sides of the shelters and against vertical flanges at the front of both, leaving a $1.3-\mathrm{cm}$ space between the bottom of the inserts and the bottom of the shelter and a $2.5-\mathrm{cm}$ space between the front insert and the front panel of the shelter. As well, there was a ca. $1.3-\mathrm{cm}$ space between the top of the inserts and the roof. The spacers on each insert created a ca. $0.3-\mathrm{cm}$ gap between adjacent inserts, with some variation due to deformations.

\section{Insects}

For studies in winter 2012 and 2013, adult $H$. halys were collected on 13 December 2011 and 17 January 2013, respectively, from stacks of cardboard boxes in a fruit packing shed in Rappahannock County (VA, USA). To collect adults for the study in 2014, the wooden overwintering shelters described above were deployed in several counties in northern VA from mid-September to midNovember 2013, against the walls of buildings that had been heavily invaded by $H$. halys in previous years. The collection for 2014 was supplemented in January with adults from overwintering aggregations at a lumberyard in Keedysville (MD, USA).

In 2011, collected adults were held for $24 \mathrm{~h}$ in a dark, controlled-environment chamber at $4{ }^{\circ} \mathrm{C}$ at Virginia Tech's Alson H. Smith Agricultural Research and Extension Center (AHSAREC; Winchester, VA, USA), then sorted by sex and placed in the plastic overwintering shelters in groups of 50 males and 50 females per shelter. The funnel was affixed to the container and a cork plug was used to close the funnel opening. The bugs were allowed to re-settle for several hours, after which the shelters were held in the controlled-environment room described above until deployed in the field.

For studies in 2013 and 2014, collected adults were sorted by sex into groups of 50 in 473-ml plastic containers and held in coolers outdoors. Between early and mid-February, adults that appeared healthy were marked on the pronotum using an oil-based paint marker (DecoColor; Marvy Urchida, Torrance, CA, USA). The shelters were inverted and 150 males and 150 females were distributed 
Figure 2 Wooden overwintering shelters used in 2013 and 2014. (A) Front view with removable front panel on (left) and off, showing vertical cardboard insert (right), (B) bottom view with 18 vertical cardboard inserts (dashed arrows indicate flanges at the bottom of both sides, upon which the inserts rested, and on the front of both sides, which created a gap between the bottom of the inserts and the bottom of the shelter and between the first insert and the front panel, and (C) side view. (D) View of gap between the front panel and roof. (E) Components of the assembly within which overwintering shelters were deployed: (1) screened cage with shelter, (2) apple crates, (3) metal screen cylinder, (4) coroplast cover, and (5) temperature sensor. (F) Assembled components in the field. Arrows indicate two of the eight black pyramid traps that encircled each shelter assembly at $45^{\circ}$ intervals.
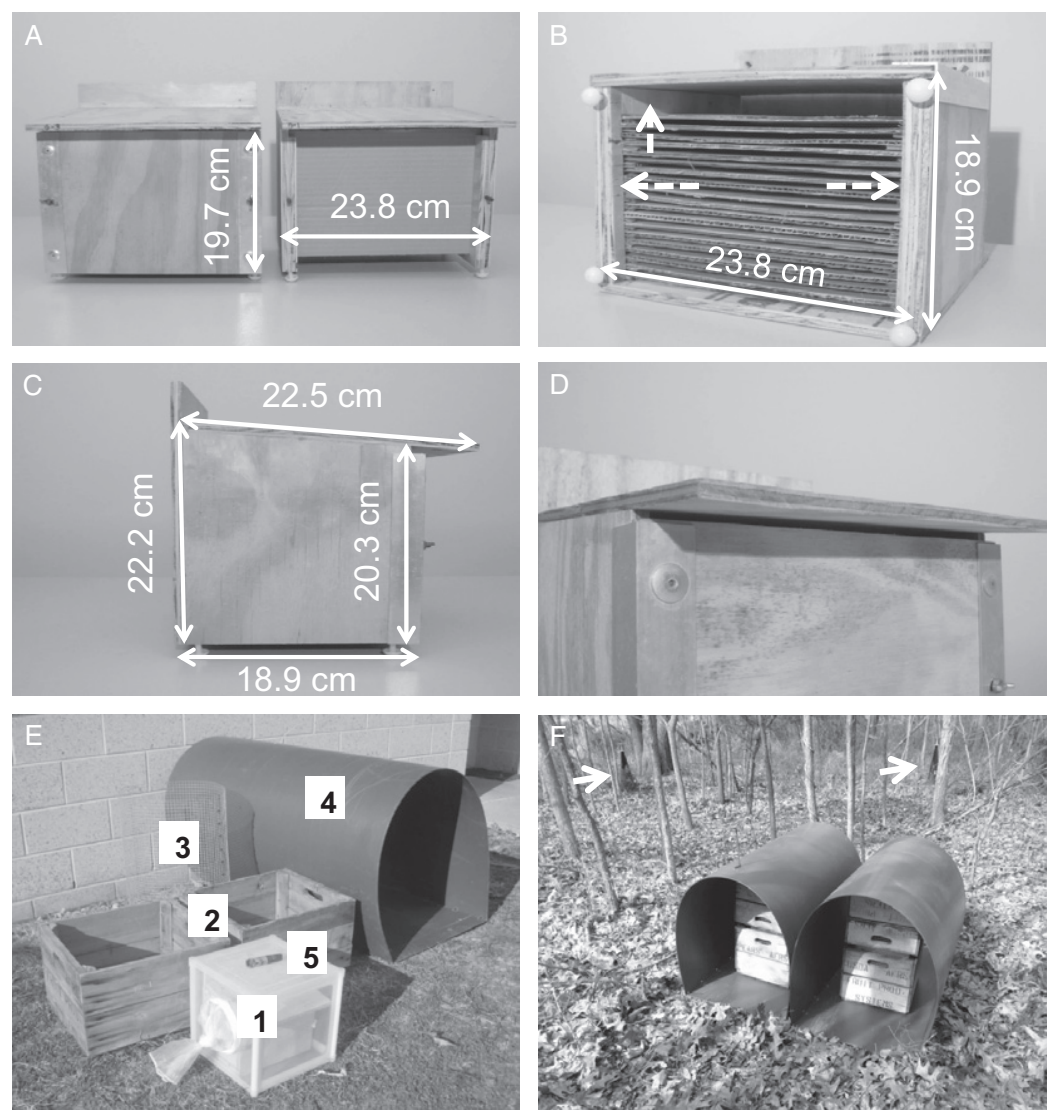

among the spaces between the cardboard inserts in each. The bottom was sealed with a piece of fitted cardboard affixed with furniture glide pins and a strip of cotton dental wick was used to close the opening at the top of the front panel. The shelters were then righted to their standard orientation and held in a warm greenhouse for 2-4 h to enable the insects to re-settle within them, after which they were held in a darkened room at $4{ }^{\circ} \mathrm{C}$ until deployed in the field in late February.

\section{Field sites and shelter deployment}

The shelters and protective structure assemblies used in all years of study were intended to simulate the tight, dry, and mostly dark spaces within which adult $H$. halys naturally aggregate and overwinter (Lee et al., 2014b), while enabling them to perceive ambient light and temperature cues. In 2012, three unheated, unlighted buildings (as in Figure 1D) with an adjacent woodlot were selected near Winchester, VA. Buildings included a closed storage barn at the AHSAREC, an abandoned farmhouse in the middle of a commercial apple and peach orchard, and a semiclosed barn containing stacks of apple crates on a commercial apple farm. On 26 January 2012, the plug was removed from the funnel opening and one shelter was deployed in the building and one in the woodlot at each site. Each shelter was placed in a $29.9-\mathrm{cm}^{3}$ screened cage (BugDorm 1; BioQuip Products, Rancho Dominguez, CA, USA) with a removable top and these were placed in wooden apple crates $(30.5 \times 45.7 \times 38.1 \mathrm{~cm})$ with spaces $(\geq 0.6 \mathrm{~cm}$ wide) between the slats that formed the sides and bottom (Figure 1B). A temperature logger (EL-USB-2; Lascar Electronics, Erie, PA, USA) programmed to log data at 30min intervals was deployed on top of each cage. A second crate was used to cover the cages and a piece of plywood with weights was used for further protection from precipitation (Figure 1C).

In 2013 and 2014, sites were unmanaged woodlots consisting predominantly of mature deciduous tree species that had relatively little under story. In VA and WV, the sites were adjacent to apple and peach orchards, and the site in MD was adjacent to an apple orchard and row crops. In both years, shelters were deployed at three sites near Winchester, VA, USA, two sites at the Appalachian Fruit Research Station (Kearneysville, WV, USA), and one site at the Western Maryland Research and Education Center (Keedysville, MD, USA). The same sites in WV and $\mathrm{MD}$ were used in both years, whereas two new sites in VA were used in 2014. 
The shelters containing adult $H$. halys were deployed in the interior of the field sites between 19 and 21 February 2013 and on 24 February 2014, and were (mean \pm SE $=$ ) $53.5 \pm 10.0 \mathrm{~m}$ from the nearest edge of the woodlots. At deployment, the cotton wick was removed from the opening at the top of the front panel of each shelter and the cardboard piece was removed from the bottom. The furniture glide pins were re-inserted at the bottom corners so that the bottom of each shelter was slightly elevated above the floor of the cage in which it was placed. At each site, shelters were deployed in pairs in the screened cages described above. One shelter was placed in a cage with the top on, hereafter referred to as a 'closed cage'. Adults that emerged from the shelters into the closed cages could not escape and thus could be collected and counted. The other shelter was placed in a cage with the top off, hereafter referred to as an 'open cage'. This assembly enabled adults that emerged from the shelters to disperse from the cage, with the assumption that the temporal pattern of adult emergence from the shelters would be similar for those in open and closed cages.

Figure 2E shows the components of the protective assembly within which the shelters were deployed in 2013 and 2014. The cages containing shelters were placed in the wooden apple crates described above and an open-ended, tight-fitting, wire mesh cylinder $(61 \mathrm{~cm}$ high, $40.6 \mathrm{~cm}$ diameter) with $1.1-\mathrm{cm}^{2}$ openings was inserted to the bottom of each crate, thereby enclosing the cage and impeding access by potential vertebrate predators. A second apple crate was inverted over the cylinder to the bottom of the crate. At each site, crate assemblies containing shelters in open and closed cages were placed individually in a pair of side-by-side, elongated and open-ended dome structures ( $1.2 \mathrm{~m}$ long, $0.4 \mathrm{~m}$ tall at the apex) with a flat bottom ( $0.6 \mathrm{~m}$ wide) (Figure $2 \mathrm{~F}$ ). These were constructed from sheets of dark brown coroplast $(4 \times 2.4 \mathrm{~m} \times 1.2 \mathrm{~mm}$; Milmar Plastics, Hagerstown, MD, USA) that had been folded lengthwise and attached along both sides using metal grommets and plastic cable ties. At each site, a temperature sensor (described above) was suspended beneath the top of the dome containing the shelter in the open cage and another was affixed to the front of the first cardboard insert inside the shelter within the same dome. Sensors were programmed to log data at 30-min intervals throughout each study. Photoperiod data for the region in which the study was conducted were obtained from www.timeanddate.com/sun/usa/washing ton-dc.

\section{Adult emergence}

In 2012, adult $H$. halys that had emerged from the shelter into the cage were removed and counted at about 7-day intervals between 2 February and 12 July. In 2013, sampling from the closed cages began on 28 February, about 7 days after the shelters were deployed. Heavy snowfall in 2014 precluded the first sample until the week of 10 March, about 14 days after shelter deployment. At weekly intervals through 11 April 2013 and 14 April 2014, live and dead $H$. halys adults were removed and counted. Thereafter, to increase the likelihood that emerged adults would be alive on each sample date, these data were collected twice weekly through late June or early July. At the end of the studies in 2013 and 2014, all shelters in open and closed cages were opened and the number of live and dead adults remaining in them was recorded.

\section{Captures in pheromone traps}

In 2013 and 2014, eight black pyramid traps (1.2 m high; AgBio) were deployed in a circle (ca. $10 \mathrm{~m}$ radius) at $45^{\circ}$ intervals around the shelter assemblies at each site, with ca. $15 \mathrm{~m}$ between traps (Figure 2F). Traps were deployed between 19 and 21 February 2013 and between 24 February (WV and MD) and 10 March 2014 (VA). Traps in the circle alternated between non-baited controls and baited traps containing a gray rubber septum with $10 \mathrm{mg}$ of the $H$. halys aggregation pheromone (Khrimian et al., 2014) plus a lure containing $126 \mathrm{mg}$ of the pheromone synergist, methyl (2E,4E,6Z)-decatrienoate (Weber et al., 2014) (Sterling International, Spokane, WA, USA). Lures were suspended within the plastic collection jar atop the traps and all jars were ventilated via a 3.2-cm-diameter hole on all four sides with black plastic mesh ( $1 \mathrm{~mm}^{2}$ openings $)$ glued over them. All traps contained a ca. 5.1-cm-long strip of Hercon Vaportape II (Hercon Environmental, Emigsville, PA, USA) containing dimethyl 2,2-dichlorovinyl phosphate, also suspended from the top of the jar, which served as the killing agent. The aggregation pheromone lures and toxicant strips were replaced at 2-week intervals and the methyl decatrienaote lures were replaced monthly (Joseph et al., 2013). Understory vegetation that grew during the study and occluded the line of sight between the shelter assemblies and the traps was removed. The number of marked and 'wild' (i.e., unmarked) $H$. halys adults in each trap was recorded at weekly intervals through the end of June 2013 and 2014.

\section{Statistical analysis}

Analyses were performed in JMP Genomics v.5.0 (SAS Institute, Cary, NC, USA) or R Software (R Core Team, 2015) and statistical outcomes were considered significant at $\mathrm{P}<0.05$. The total numbers of adults that emerged from shelters in woodlots and buildings were compared using Student's t-test. As the emergence and dispersal of adults from shelters in the open cages in 2013 and 2014 was not 
recorded during the sampling period, a Student's t-test was used to compare the numbers of adults remaining in shelters in open and closed cages at the end of the study, when the emergence of adults into the closed cages had essentially ceased. A t-test was also used to compare the numbers of live and dead adults recovered from the closed cage during the sampling period. Twice-weekly records of emergence taken during most of the sampling period in 2013 and 2014 were converted to weekly counts for analysis. Total captures of adult $H$. halys in baited and non-baited traps were compared using Student's t-test for each sampling year and the numbers of marked and unmarked adults captured were compared using a $\chi^{2}$ test of the null hypothesis of equal frequencies of marked and unmarked individuals. Pearson correlation coefficients were used to examine the relationship between adult emergence and captures in traps over the entire sampling period and their significance was assessed by calculating a P-value based on a Student's t distribution. Since the data did not conform to a normal distribution, they were transformed prior to analysis using $\log (x+0.1)$. Mean maximum weekly temperature readings from sensors associated with shelters in buildings and woodlots in 2012 and from sensors inside and outside shelters in woodlots in 2013-2014 were compared using a t-test.

\section{Results}

\section{Temperature sensor comparisons}

The mean maximum weekly temperatures recorded were not significantly different between sensors associated with shelters in buildings vs. woodlots in $2012(\mathrm{t}=0.773$, d.f. $=44, \mathrm{P}=0.44$ ) or between sensors inside vs. outside shelters in $2013(\mathrm{t}=0.730$, d.f. $=38, \mathrm{P}=0.47)$ and 2014 $(t=0.937$, d.f. $=30, P=0.36)$.

\section{Adult survivorship}

The experimental shelters appeared to provide suitable harborage for overwintering adult $H$. halys. In 2012, of the 100 adults per plastic shelter (mean $\pm \mathrm{SD}=$ ) $60.3 \pm 30.4$ and $64.0 \pm 26.2$ emerged from those deployed in buildings and woodlots, respectively, with no significant difference between the two settings $(t=0.153$, d.f. $=4$, $\mathrm{P}=0.89$ ). During the 2013 and 2014 sampling periods (mean $\pm \mathrm{SD}=$ ) $263.7 \pm 28.9$ and $252.3 \pm 29.7$, respectively, of the 300 adults per wooden shelter were collected from the closed cages, excluding those individuals that were recovered and discounted at the beginning of the studies. Of the individuals collected from those cages during the sampling period, more were recovered alive than dead in 2013 (mean $\pm \mathrm{SD}=88.3 \pm 4.52 \%$ alive; $\mathrm{t}=19.5$, d.f. $=5, \mathrm{P}<0.0001)$ and $2014(72.9 \pm 14 \%$ alive; $\mathrm{t}=4.64$, d.f. $=5, \mathrm{P}<0.001)$. In 2013 , the number of adults remaining in the shelters at the end of the study did not differ significantly between closed and open cages (mean $\pm \mathrm{SD}=32.0 \pm 34.5$ vs. $39.5 \pm 25.2 ; \mathrm{t}=1.72$, d.f. $=5, \mathrm{P}=0.12$ ), and $97.2 \pm 1.83 \%$ (SD) of these were dead, implying that similar numbers had survived and exited the shelters deployed in each cage type. At the end of the study in 2014, more adults were found in shelters in open than in closed cages (mean $\pm \mathrm{SD}=105 \pm 75.4$ vs. $41.7 \pm 33.1 ; \mathrm{t}=2.70$, d.f. $=5, \mathrm{P}=0.03$ ), all of which were dead.

\section{Adult emergence}

In 2012, the temporal patterns of emergence from shelters in buildings and woodlots were similar (Figure 3A and B). Few adults emerged during March and early April and there was a small and short-lived increase in emergence in mid-April. Sustained and generally increasing emergence from shelters in both settings began in early May and peaked in late May. Thereafter, emergence subsided rapidly and was essentially finished by 28 June. In 2013, the temporal pattern of adult emergence from the wooden shelters in closed cages was remarkably similar across the six sites (Figure 3C) and similar to that recorded from plastic shelters in 2012. There was an initial, relatively small peak of emergence of short duration in mid-April, followed by a period of very low numbers through about mid-May and a larger, more prolonged peak between mid-May and early June, after which emergence declined rapidly. Compared with 2013, relatively large numbers of dead adults were found in the cages at three of six sites during the first 2 weeks of sampling in 2014 (Figure 3D), which we ascribed to weak individuals that had died and fallen out the bottom of the shelters. Although the initial reduction in the cohort in those shelters presumably affected the potential magnitude of subsequent emergence peaks, the overall pattern of emergence from shelters in closed cages thereafter was similar to that observed in 2012 and 2013. An initial, small peak of emergence was recorded in mid-April, followed by somewhat reduced numbers through about mid-May and a second, somewhat larger and more prolonged peak between about mid-May and early June, after which emergence again declined through late June.

\section{Captures in pheromone traps}

Between years, $449 \mathrm{H}$. halys adults were captured in the traps that encircled the shelters (Figure 4). Each year, the total number of adults captured varied substantially among the sites, ranging from 6 to 91 in 2013 and from 2 to 70 in 2014. Significantly more adults were caught in baited $(98 \%)$ than in non-baited traps in $2013(\mathrm{t}=2.97$, 


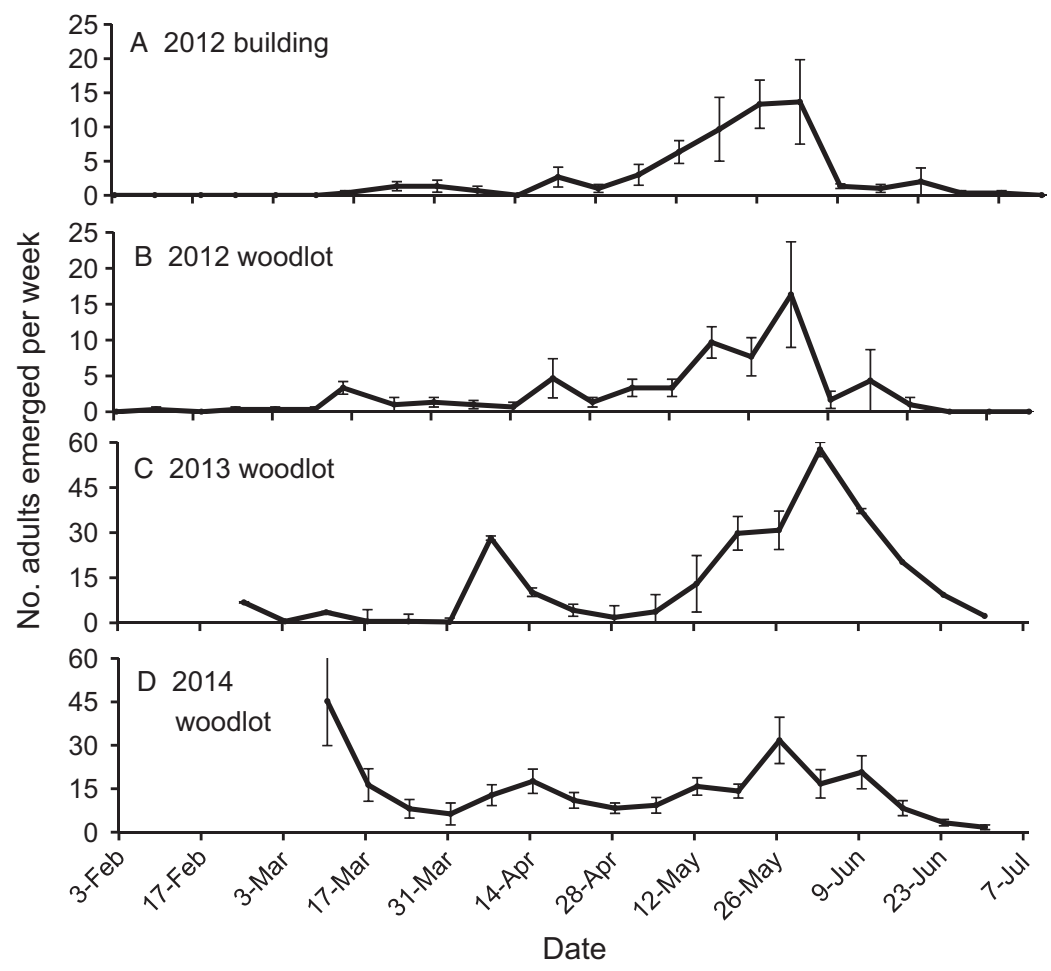

Figure 3 Weekly emergence of adult Halyomorpha halys (mean number $\pm \mathrm{SE}$ ) from experimental overwintering shelters deployed in (A) three unheated, unlighted buildings in 2012, (B) a woodlot near each building in 2012, (C) six woodlots in 2013, and (D) six woodlots in 2014. Deployment sites in 2012 were near Winchester (VA, USA) and in 2013 and 2014 they were near Winchester, Kearneysville (WV, USA), and Keedysville (MD, USA). Note the difference in scale on the $y$-axis between $\mathrm{A}$ and B vs. C and D. d.f. $=11)$ and $2014(93 \%)(t=2.52$, d.f. $=11$, both $\mathrm{P}<0.05)$. Of the 1531 and 1463 marked $H$. halys adults that emerged and presumably dispersed from the shelters in open cages across the six sites in 2013 and 2014, respectively, none were found in the traps in 2013 and only three were captured in 2014. In both years, fewer marked adults were captured than expected at random (2013: $\chi^{2}=1$ 572; 2014: $\chi^{2}=1$ 454; both d.f. $=1, \mathrm{P}<0.0001$ ). When the entire sampling period was considered, captures of 'wild', unmarked adults in the traps were not correlated with adult emergence from shelters in closed cages in 2013 $(\mathrm{r}=0.007$, d.f. $=17, \mathrm{P}=0.98)$ or $2014(\mathrm{r}=-0.064$, d.f. $=15, \mathrm{P}=0.80)$.

\section{Discussion}

The experimental shelters proved useful for monitoring the temporal pattern of spring emergence of overwintering adult $H$. halys and yielded quite consistent results among years. The protracted and asynchronous emergence of $H$. halys adults between about mid-April and late June suggests the potential for overlapping generations, as predicted by Nielsen et al. (2016), although photoperiod effects on $H$. halys diapause termination and female ovarian development (Watanabe, 1979; Yanagi \& Hagihara, 1980) and temperature effects on female reproductive maturation and pre-oviposition period (Yanagi \&
Hagihara, 1980; Nielsen et al., 2008) may moderate this to some degree (Nielsen et al., 2016). The period of emergence was somewhat different than that reported from Asia, where it extended from late March until mid-May (Lee et al., 2013). However, the major peak of emergence from about mid-May through early June conformed with previous observations of increasing numbers of adult $H$. halys invading tree fruit orchards in late May in the Mid-Atlantic region (Leskey et al., 2012a).

Our studies were not designed specifically to address the effects of abiotic factors on $H$. halys emergence, but in combination with what is currently known about environmental effects on its diapause termination, ovarian development, and emergence, these data represent new baseline information. Watanabe (1979) and Yanagi \& Hagihara (1980) suggested that the critical photoperiod for diapause termination of overwintering $H$. halys ranged from 13.5 to $14.75 \mathrm{~h}$ and Watanabe (1979) reported that ovarian development was initiated between 13.5 and $14.0 \mathrm{~h}$. This purported critical photoperiod range, which occurs between 22 April and 22 May in this region, spanned the period during which sustained and generally increasing emergence per week occurred across all years, raising the question of whether the physiological events triggered by photoperiod are also associated with a behavioral transition from remaining settled to emerging from overwintering sites. We conducted post-hoc analyses (data not 
Figure 4 Weekly emergence of adult Halyomorpha halys (mean number) from experimental overwintering shelters and captures of adult $H$. halys (mean number \pm SE) in pheromone-baited plus non-pheromone-baited pyramid traps that encircled the shelters in (A) 2013 and (B) 2014 at field sites in Virginia, West Virginia, and Maryland, USA.

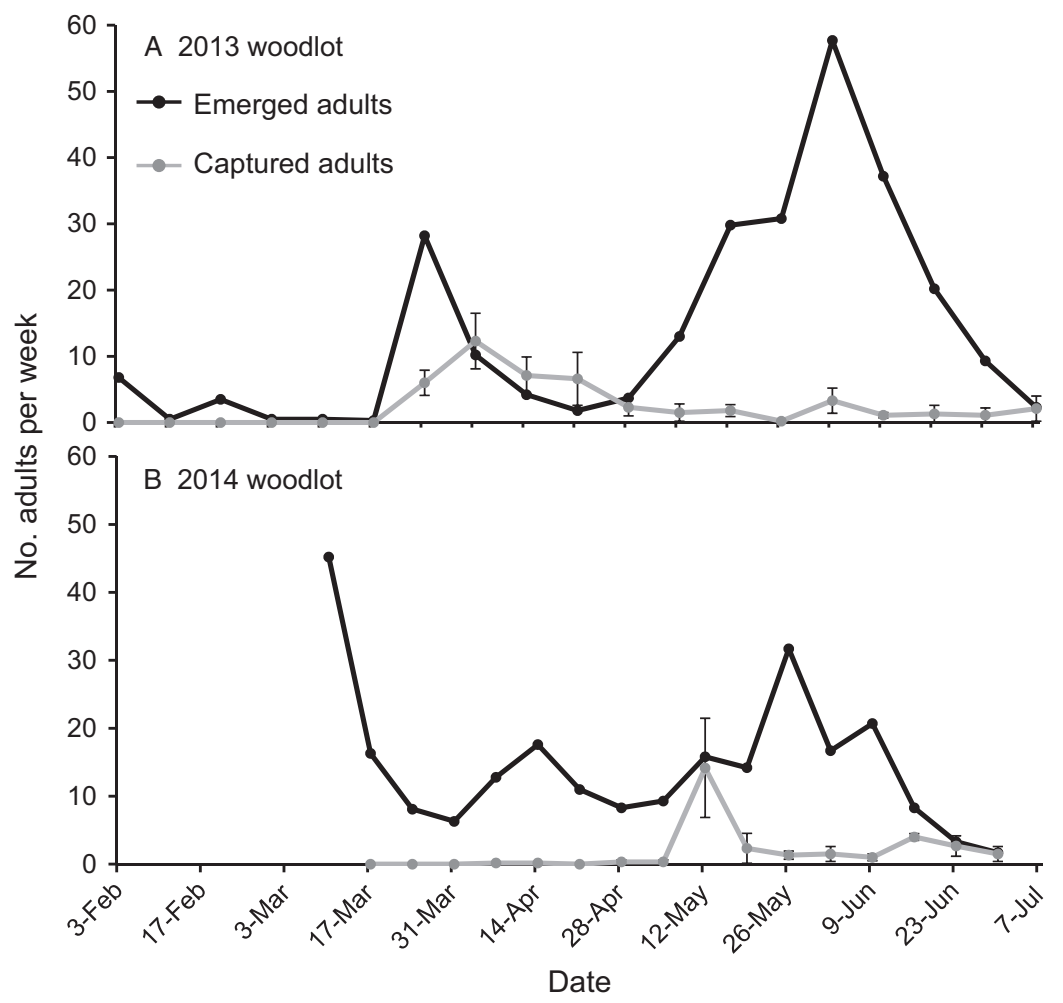

shown) of the correlation between the observed emergence patterns and local day length and found significant positive relationships for the two datasets from 2012 (woodlots and buildings) and the dataset from 2013, but not for the dataset from 2014, perhaps due to the inclusion of the adults recovered early in the 2014 study.

In China, $H$. halys emergence from overwintering sites was observed at temperatures above $10^{\circ} \mathrm{C}$ (Lee et al., 2013). Our post-hoc examination of the correlation between emergence and weekly mean maximum temperature during the sampling periods (data not shown) also revealed significant positive relationships between these variables for the datasets from 2012 and 2013, but not for the dataset from 2014. Interestingly, the majority of individuals appeared to 'wait' to emerge until mid-to-late May, despite apparently suitable temperatures prior to that period. This may suggest that critical degree-day accumulations serve as an emergence trigger. Indeed, we have repeatedly observed that adult $H$. halys collected directly from overwintering aggregations in early May become active almost immediately and that those collected from such aggregations during the winter typically require about 2 weeks of exposure to $>23{ }^{\circ} \mathrm{C}$ and a L16:D8 photoperiod to exhibit an active foraging state (Leskey et al., $2012 b$ ). There were suggestions that some of the smaller emergence peaks in early to mid-April may have been associated with brief periods of higher temperatures. As suggested by Funayama (2012), if overwintering H. halys adults vary in their capacity to withstand a prolonged diapause based on differences in size, nutritional status, or sex at the onset of overwintering, it is possible that some portion of the population may become depleted of resources and emerge sooner in response to suitably high temperatures.

Captures of unmarked adults in pheromone traps varied substantially among sites during the sampling period and we hypothesize that differences in these captures reflected, to some degree, the size of the overwintering population in the general vicinity of the traps. However, the finding that only three marked adults were captured suggests that adults may need to disperse from the immediate vicinity of the overwintering site before responding to pheromonal stimuli. Indeed, monthly flight mill studies over 1 year using field-collected adult $H$. halys revealed maximum flight distances by those collected from overwintering aggregations in May (presumably those in a state of readiness to emerge) and those directly from host plants in June (presumably those that had emerged relatively recently) (Lee \& Leskey, 2015). On average, adults tested in May and June flew 4 and $6 \mathrm{~km}$, respectively.

Large differences among study sites in total captures of unmarked $H$. halys adults in pheromone traps during the 
emergence period of marked adults likely had a strong effect on the lack of correlation between captures and emergence. Initial captures coincided with the early emergence peak in 2013 but not in 2014. In both years, peak captures of unmarked adults occurred before peak emergence of marked adults into cages. Therefore, the data suggest that using first captures of adult $H$. halys in pheromone traps as a biofix for initializing population development models may not be promising, given that initial and subsequent captures will be affected by the size of the local population, the effect of temperature on $H$. halys flight capacity (Lee \& Leskey, 2015) and likely on pheromone release rates, and on important knowledge gaps in our understanding of adult $H$. halys post-emergence behavior (e.g., dispersal from the overwintering site, latency of response to pheromonal stimuli after emergence, initial selection of host plants).

Recently, wooden shelters deployed against exterior building walls during the fall dispersal of $H$. halys have demonstrated their utility for collecting naturally settled cohorts of adults. When used in association with heavily invaded buildings, hundreds to $>2000$ adults have aggregated within a single shelter, clearly indicating its suitability as an overwintering location. However, we believe that their effectiveness for experimentation can be improved by closing the bottom after adults have settled in them. For the present experiments, we initially felt that enabling adults to exit the wooden shelters either via the open bottom or the gap at the top of the front panel was a potentially important consideration. On average, about $80 \%$ of the adults found in the cages were alive, but there were also numerous dead individuals; thus, we could not determine whether those had died after exiting the shelter or had died in the shelter and then fallen out the bottom. Recent studies confirmed that when the bottom of the shelter is closed, overwintered adults will readily exit through the gap at the top of the front panel, thereby removing this source of uncertainty. This modification also increases the accuracy of measuring the survivorship of adults in response to biotic or abiotic factors, because any that die will be within the shelter at the study conclusion.

These studies have enhanced our understanding of the onset, peak, and duration of adult $H$. halys emergence from overwintering sites in this region and demonstrated the utility of the shelters to investigate other aspects of its overwintering ecology. For example, exposing cohorts of adult $H$. halys that settle voluntarily in these shelters during the fall dispersal period to controlled photoperiod and temperature regimes during the winter and spring should yield deeper insights into the relative contribution of each environmental cue to their spring emergence, thereby potentially enabling the determination of a biofix for population modeling. In addition, the use of voluntarily settled cohorts of adults would enable examination of the sex ratio and size distribution within these aggregations as well as the time of emergence in relation to adult size, weight, and sex, all of which may be relevant to modeling $H$. halys population dynamics.

\section{Acknowledgements}

We thank Jean Engelman, John Cullum, Torri Hancock, and Samuel Brandt for excellent technical assistance with this project. This research was supported by award \#2011-51181-30937 from the USDA-NIFA SCRI Program. Mention of trade names or commercial products in this publication is solely for providing scientific information and does not imply recommendation or endorsement by the US Department of Agriculture.

\section{References}

Acebes-Doria AL, Leskey TC \& Bergh JC (2016a) Injury to apples and peaches at harvest from feeding by Halyomorpha halys (Stål) (Hemiptera: Pentatomidae) nymphs early and late in the season. Crop Protection 89: 58-65.

Acebes-Doria AL, Leskey TC \& Bergh JC (2016b) Host plant effects on Halyomorpha halys (Hemiptera: Pentatomidae) nymphal development and survivorship. Environmental Entomology 45: 663-670.

Cira TM, Venette RC, Aigner J, Kuhar T, Mullins DE et al. (2016) Cold tolerance of Halyomorpha halys (Hemiptera: Pentatomidae) across geographic and temporal scales. Environmental Entomology 45: 484-491.

Funayama K (2012) Nutritional states of post-overwintering adult brown-marmorated stink bugs, Halyomorpha halys (Stål) (Heteroptera: Pentatomidae). Japanese Journal of Applied Entomology and Zoology 56: 12-15.

Hoebeke ER \& Carter ME (2003) Halyomorpha halys (Stål) (Heteroptera: Pentatomidae): a polyphagous plant pest from Asia newly detected in North America. Proceedings of the Entomological Society of Washington 105: 225-237.

Inkley DB (2012) Characteristics of home invasion by the brown marmorated stink bug (Hemiptera: Pentatomidae). Journal of Entomological Science 47: 125-130.

Joseph SV, Bergh JC, Wright SE \& Leskey TC (2013) Factors affecting captures of brown marmorated stink bug, Halyomorpha halys (Hemiptera: Pentatomidae), in baited pyramid traps. Journal of Entomological Science 48: 43-51.

Joseph SV, Nita M, Leskey TC \& Bergh JC (2015) Temporal effects on the incidence and severity of brown marmorated stink bug (Hemiptera: Pentatomidae) feeding injury to peaches and apples during the fruiting period in Virginia. Journal of Economic Entomology 108: 592-599.

Khrimian A, Zhang A, Weber DC, Ho H-Y, Aldrich JR et al. (2014) Discovery of the aggregation pheromone of the brown marmorated stink bug (Halyomorpha halys) through the 
creation of stereoisomeric libraries of 1-bisabolen-3-ols. Journal of Natural Products 77: 1708-1717.

Lee D-H \& Leskey TC (2015) Flight behavior of foraging and overwintering brown marmorated stink bug, Halyomorpha halys (Hemiptera: Pentatomidae). Bulletin of Entomological Research 105: 566-573.

Lee D-H, Wright SE \& Leskey TC (2012) Impact of insecticide residue exposure on the invasive pest, Halyomorpha halys (Hemiptera: Pentatomidae): analysis of adult mobility. Journal of Economic Entomology 106: 150-158.

Lee D-H, Short BD, Joseph SV, Bergh JC \& Leskey TC (2013) Review of the biology, ecology, and management of Halyomorpha halys (Stål) (Hemiptera: Pentatomidae) in China, Japan, and the Republic of Korea. Environmental Entomology 42: 627-641.

Lee D-H, Nielsen AL \& Leskey TC (2014a) Dispersal capacity and behavior of nymphal stages of Halyomorpha halys (Hemiptera: Pentatomidae) evaluated under laboratory and field conditions. Journal of Insect Behavior 27: 639-651.

Lee D-H, Cullum JP, Anderson JL, Daugherty JL, Beckett LM \& Leskey TC (2014b) Characterization of overwintering sites of the invasive brown marmorated stink bug in natural landscapes using human surveyors and detector canines. PLoS ONE 9: e91575.

Leskey TC, Short BD, Butler BR \& Wright SE (2012a) Impact of the invasive brown marmorated stink bug, Halyomorpha halys (Stål), in mid-Atlantic tree fruit orchards in the United States: case studies of commercial management. Psyche 2012: 1-14.

Leskey TC, Lee D-H, Short BD \& Wright SE (2012b) Impact of insecticides on the invasive Halyomorpha halys (Stål) (Hemiptera: Pentatomidae): analysis of insecticide lethality. Journal of Economic Entomology 105: 1726-1735.

Leskey TC, Short BD \& Lee D-H (2013) Efficacy of insecticide residues on adult Halyomorpha halys (Stål) (Hemiptera: Pentatomidae) mortality and injury in apple and peach orchards. Pest Management Science 70: 1097-1104.

Leskey TC, Agnello JA, Bergh JC, Dively GP, Hamilton GC et al. (2015a) Attraction of the invasive Halyomorpha halys (Hemiptera: Pentatomidae) to traps baited with semiochemical stimuli across the United States. Environmental Entomology 44: 746-756.

Morrison WR III, Cullum JP \& Leskey TC (2015) Evaluation of trap designs and deployment strategies for capturing Halyomorpha halys (Hemiptera: Pentatomidae). Journal of Economic Entomology 108: 1683-1692.

Morrison WR III, Lee D-H, Short BD, Khrimian A \& Leskey TC (2016) Establishing the behavioral basis for an attract-and-kill strategy to manage the invasive Halyomorpha halys in apple orchards. Journal of Pest Science 89: 81-96.

Nielsen AL, Hamilton GC \& Matadha D (2008) Developmental rate estimation and life table analysis for Halyomorpha halys (Hemiptera: Pentatomidae). Environmental Entomology 37: 348-355.

Nielsen AL, Chen S \& Fleischer SJ (2016) Coupling developmental physiology, photoperiod, and temperature to model phenology and dynamics of an invasive heteropteran, Halyomorpha halys. Frontiers in Physiology 7: 1-12.

R Core Team (2015) R: A Language and Environment for Statistical Computing. R Foundation for Statistical Computing, Vienna, Austria.

Taylor CM, Coffey PL, DeLay BD \& Dively GP (2014) The importance of gut symbionts in the development of the brown marmorated stink bug, Halyomorpha halys (Stål). PLoS ONE 9: e90312.

Watanabe M (1979) Ecology and extermination of Halyomorpha halys. 4. The relationship between day length and ovarian development. Annual Report of the Toyama Institute of Health 3: 33-37.

Weber DC, Leskey TC, Walsh GC \& Khrimian A (2014) Synergy of aggregation pheromone with methyl (E,E,Z)-2, 4, 6-decatrienoate in attraction of Halyomorpha halys (Hemiptera: Pentatomidae). Journal of Economic Entomology 107: 1061-1068.

Wiman NG, Walton VM, Shearer PW, Rondon SI \& Lee JC (2015) Factors affecting flight capacity of brown marmorated stink bug, Halyomorpha halys (Hemiptera: Pentatomidae). Journal of Pest Science 88: 37-47.

Yanagi T \& Hagihara Y (1980) Ecology of the brown marmorated stink bug. Plant Protection 34: 315-326. 